\title{
NUMERICAL ANALYSIS OF THE POSTBUCKLING OF THIN-WALLED COMPOSITE STRUCTURE WITH Z-PROFILE CROSS SECTION
}

\author{
Patryk Różyło ${ }^{1}$ \\ 1 Faculty of Mechanical Engineering, Lublin University of Technology, Nadbystrzycka 36, 20-618 Lublin, Poland, \\ e-mail: p.rozylo@pollub.pl
}

Received: 2017.09 .25

Accepted: 2018.04.04

Published: 2018.06.01

\begin{abstract}
The object of the study was a thin-walled sample made of carbon composite. The studied profile was a z-shaped cross section. The aim of the study was a post critical state analysis by the use of four independent destruction initiation criteria. The numerical analysis was conducted in ABAQUS ${ }^{\circledR}$. The study presents the critical areas of the composite sample and determines the load values at which initiation criteria were met. The post critical state examination was confronted with previously obtained results of the critical state. In addition, the effect of the laminate layer configuration on the stability and load capacity of the structure is shown.
\end{abstract}

Keywords: Finite element method, Numerical analysis, Initiation criteria of destruction.

\section{INTRODUCTION}

A contemporary engineering approach continuously seeks new possibilities and improvement of existing techniques that allow for an unambiguous assessment of the strength of materials. The potential resulting from existing advanced numerical computational systems demonstrates high-quality possibilities for critical and boundary states in the case of isotropic structures. The attempt to estimate the critical areas and unambiguous assessment of the boundary states is getting more complex with the use of composite materials. Composites are characterized by orthotropic properties varied layered laminate layouts and operations exceeding the critical range until the load capacity is completely reduced $[2,4,10 \div 12$, $15 \div 18,23]$. These features represent a completely separate behaviour of structures made of composite materials from structures made of traditional materials $[7,14,20,24]$. The advantage resulting from the use of composite structures is the ability to control the layer system without changing the thickness of the laminate to achieve better stiffness or energy-absorbing properties.
Structural stability is the issue concerning the possibility of determination of the operations load limits values, initially within the critical state and the evaluation of the structure's operations in the post-critical state, with axial compression $[3,8$, $21,25,26,29]$. The range of work of the composite structure can be broadly divided into three overriding stages. In the first stage, the composite structure on the example of the plate structure operates in the pre-critical state. In this state, only the process of compressing the structure of the laminate takes place without any rise in deflection. The second state commonly known as buckling is burdened by the phenomenon of loss of stability, where bifurcation takes place - changing linear range of work to non-linear. Once the bifurcation point has been reached, the structure has the opportunity to continue the operations in the post-critical range - at the same time it constitutes the third characteristic state of operations of the composite structures. In some cases the postcritical state value can even be several times the entire range of operations in critical state. This implies that the load capacity of the laminate can be reached with a compressive load several times 
Table 1. Material properties [5]

\begin{tabular}{|c|c|c|c|}
\hline \multicolumn{2}{|c|}{ Mechanical properties } & \multicolumn{2}{|c|}{ Limit properties } \\
\hline $\begin{array}{c}\text { Young's modulus in } \\
\text { the direction of fiber } \\
\text { E1 [MPa] }\end{array}$ & 130710 & $\begin{array}{c}\text { Compression } \\
\text { strength in the } \\
\text { direction of fiber } \\
\text { [MPa] }\end{array}$ & 1531 \\
\hline $\begin{array}{c}\text { Young's modulus } \\
\text { in the direction } \\
\text { perpendicular to } \\
\text { the fiber } \\
\text { E2 [MPa] }\end{array}$ & 6360 & $\begin{array}{c}\text { Compression } \\
\text { strength in the } \\
\text { direction perpen- } \\
\text { dicular to the fiber } \\
\text { [MPa] }\end{array}$ & 214 \\
\hline $\begin{array}{c}\text { Poisson's ratio } \\
\text { Kirchhoff's modulus } \\
\text { [MPa] }\end{array}$ & 0.32 & $\begin{array}{c}\text { Shear strength } \\
\text { [MPa] }\end{array}$ & 100 \\
\hline
\end{tabular}

higher than the force at the loss of stability. The total loss of load capacity associated with the complete destruction of the laminate continues to show the lack of uniformity of the boundary state evaluation methodology.

Fundamental theory of laminate destruction presented in the literature is commonly known as FPF (First Ply Failure), in which the composite is destroyed at the moment of damage of its first layer, as presented by Reddy and Pandey [19]. However, numerical publications have shown that the destruction of the first layer does not exhaust the total load capability reserve of the composite structure, but significantly weakens the structure $[4,5,6]$. Due to the varied processes occurring as a result of the destruction of the laminate, such as: damage to fibers, matrix or interlayer delaminations, it is necessary to precisely estimate the factors directly affecting the weakening of the structural properties.
The paper attempted to develop the research presented in the publication [21] in the range of postcritical operations until signs of destruction initiation occur. Commonly used destruction initiating criteria, supporting the computational process, are the criteria for maximum stress [11], Tsai-Hill's [28], Azzi-TsaiHill's [9], Tsai-Wu [27]. First ply failure initiation criteria [18] make it possible to assess the damage of a laminate due to the loss of the load capacity of any single layer of the composite structure. It is possible to further analyse the work of the laminate as part of the evolution of destruction - based on the progressive destruction criterion, directly reducing the rigidity of the composite upon reaching the limit values. The analysis of the behaviour of thin-walled composite structures using the progressive criterion will be the future stage of the research.

\section{SUBJECT OF THE STUDY}

The subject of the study is a thin-wall composite structure, made of carbon-epoxy composite. The height of the test sample is $150 \mathrm{~mm}$, due to the need of obtaining the correct form of deformation in a form of half-waves appearing in the axial compression process. The thickness of a single layer of laminate is $0.131 \mathrm{~mm}$. The composite consists of 8 layers with differentiated symmetrical fibers configurations. Four different laminate layouts were investigated, two cross [0/90/0/90]s and [90/0/90/0]s and the other two [45/-45/0/90]s and [90/0/-45/45] s. Mechanical properties of the laminate were determined by experimental testing, using a universal testing machine [5]. The values of materials parameters defining the mechanical properties included in the analysis are shown in Table 1.

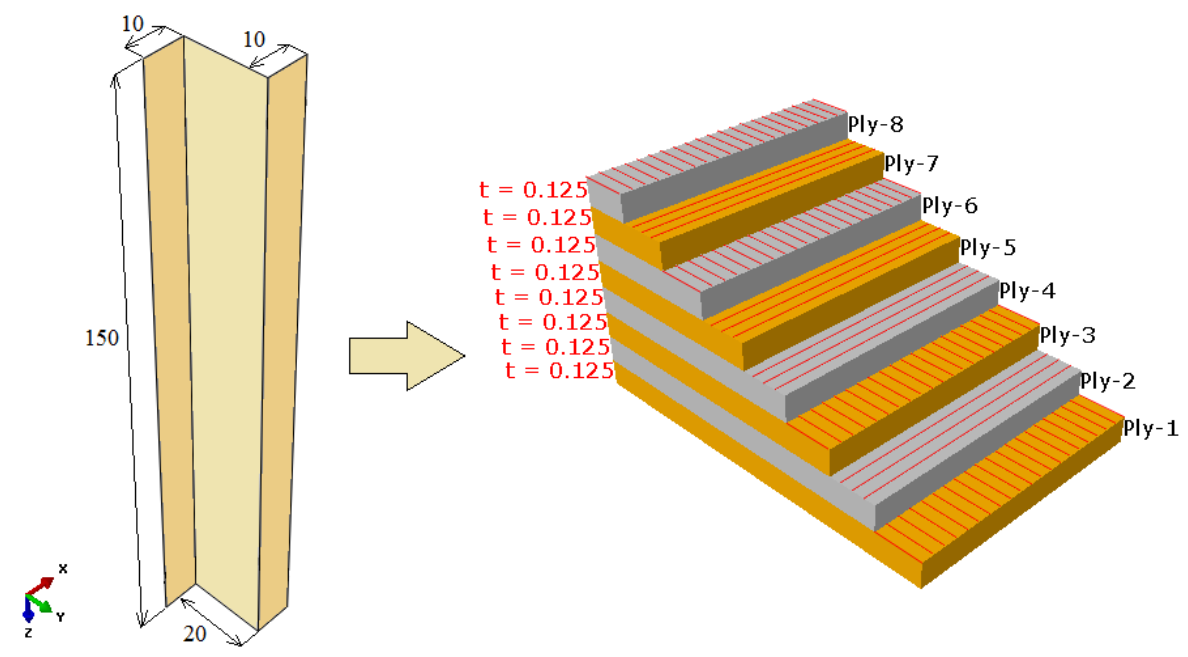

Fig. 1. Parametrized test sample with sample configuration 
The test specimen with a z-shaped cross section contains specific geometric parameters, as shown in Figure 1.

\section{METHODOLOGY OF THE RESEARCH}

Investigations of the post-critical state until reaching the limit values of load capacity have been performed in the ABAQUS ${ }^{\circledR}$ program. The study was conducted exclusively at the numerical computational stage as a continuation of the issues presented in the publication [21]. After defining the behaviour of the analysed structure in critical condition, an attempt was made to determine the post-critical structural behaviour - with particular emphasis on the loss of load capacity due to the destruction of the laminate. The continuation of the study consisted initially of taking into account the form of buckling obtained for each of the considered configurations, as a part of the further post-critical analysis. Post-critical analysis was performed based on the Newton-Raphson algorithm calculations [1,30]. The iterative incremental method has allowed to analyse the behaviour of the compressed thin-walled structures until the deeply post-critical state, taking into account the signs of laminate damage. The assessment of the degree of destruction was made on the basis of commonly known initiating criteria.

The first criterion used to estimate damage to the laminate structure at the load capacity loss is the Maximum Stress Criterion (MSTRS). This criterion is considered only in a plane state of stress and assumes that the stresses in each component of the laminate layers in the fiber direction and perpendicular to the fibers should be less than the limit values (X - in the fiber direction, $\mathrm{Y}$ - perpendicular to the fibers, $\mathrm{S}$ in the plane Layers), as shown by relations (1):

$$
-X_{c}<\sigma_{1}<X_{t}, \quad-Y_{c}<\sigma_{2}<Y_{t}, \quad-S<\tau_{12}<S
$$

where: $\sigma_{1} \mathrm{i} \sigma_{2}$-stress in the main directions of orthotropy, $\tau_{12}$ - shear stress in the plane of the layer.

The second criterion used in numerical calculations is the Tsai-Hill criterion (TSAIH). This criterion takes into account different strength levels of the laminate layer in the major directions of orthotropy of the composite material and is described by the relation (2):

$$
\frac{\sigma_{1}^{2}}{X^{2}}+\frac{\sigma_{2}^{2}}{Y^{2}}-\frac{\sigma_{1} \sigma_{2}}{X^{2}}+\frac{\tau_{12}^{2}}{S^{2}}=1
$$

The third criterion is the Azzi-Tsai-Hill criterion (AZZIT), which assumes that the strength of the laminate is mostly determined by the reach of the linear-elastic state. The form of the criterion was presented according to the relation (3):

$$
\frac{\sigma_{1}^{2}}{X^{2}}+\frac{\sigma_{2}^{2}}{Y^{2}}-\frac{\sigma_{1} \sigma_{2}}{X^{2}}+\frac{\tau_{12}^{2}}{S^{2}}=1
$$

The next, fourth initiating criterion is the Tsai-Wu criterion (TSAIW). This criterion is a tensor solution to the problem of destruction, where it is proved that any interactions due to loading occur between the stress tensor components in the major directions of orthotropy. The Tsai-Wu criterion is described by the relation (4):

$$
F_{1} \sigma_{1}+F_{2} \sigma_{2}+F_{6} \tau_{12}+F_{11} \sigma_{11}^{2}+F_{22} \sigma_{22}^{2}+F_{66} \tau_{12}^{2}+2 F_{12} \sigma_{1} \sigma_{2}=1
$$

where: $\mathrm{F}_{1}, \mathrm{~F}_{2}, \mathrm{~F}_{6} \mathrm{i} \mathrm{F}_{11}, \mathrm{~F}_{22}, \mathrm{~F}_{66}$ - are components of composite strength tensors which can be determined in the strength test for uniaxial compression, tensile and shear, respectively; F12 - strength tensor component related to the interaction of normal stresses $\sigma_{1}$ and $\sigma_{2}$, which can be determined in a biaxial test.

The above criteria were used in the numerical calculations of the post-critical state. Each of the aforementioned criteria made it possible to estimate potential areas of laminate damage. Additionally, limiting strength was determined as a result of the limit values of the material strength parameters.

The numerical model was based on the use of shell type elements. It was possible to correctly define the orthotropic properties of the material within the used element type. The boundary conditions used in the work are analogous to the original assumption presented in [21] in the critical state condition analysis. A graphical representation of the applied boundary conditions is shown in Figure 2. 


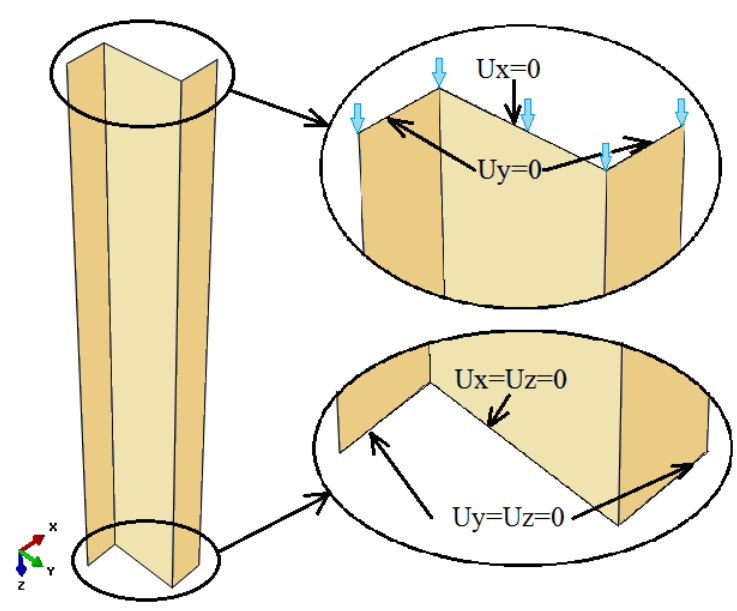

Fig. 2. Boundary conditions

The discretization process was based on the use of S8R shell elements - which are eight-layered coating elements with 6 degrees of freedom in each node, with reduced integration. In general terms, the technique of reduced integration enables the elimination of false deformation forms within the framework of existing numerical calculations [30]. As a result of the discretization process, 1500 mesh elements with a total number of computational nodes of 4691 were obtained. The graphical representation of the discrete model is shown in Figure 3.

\section{RESULTS OF THE RESEARCH}

As part of the research, potential areas of laminate damage, depending on the configuration

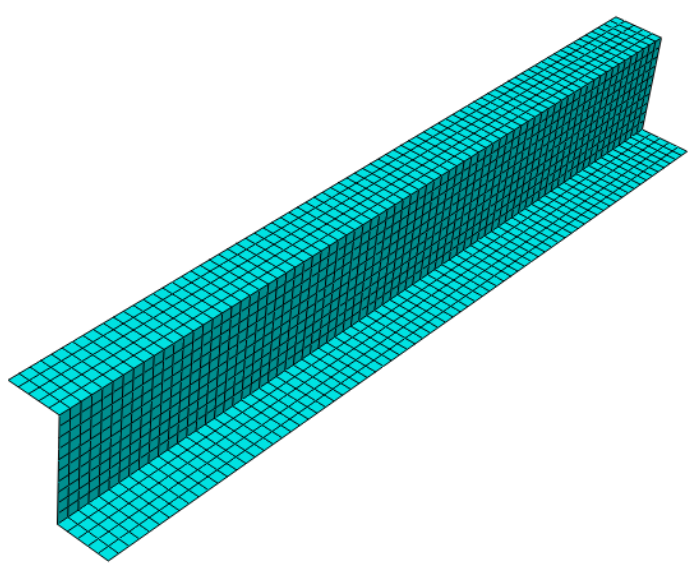

Fig. 3. Discrete model of the thin-walled composite structure

of the layers have been identified. Because of the analysis of the post-critical state exclusively, the results are related both to the designation of the damage areas and the determination of the force values at which initiation of the destruction occurred. The first case assumed an analysis of the post-critical state in the $[0 / 90 / 0 / 90]$ s configuration. Regarding the tested configuration, the initiation criteria were met with $\mathrm{P}_{\text {ini }}=8200 \mathrm{~N}$. The graphical representation of the initiation criteria compliance is shown in Figure 4.

A detailed breakdown of damage initiating values is shown in Table 2, for each of the analysed laminate layering configurations. Furthermore, damage initiation parameters for the four initialization criteria were included. In case the value of the destructor initialization parameter for
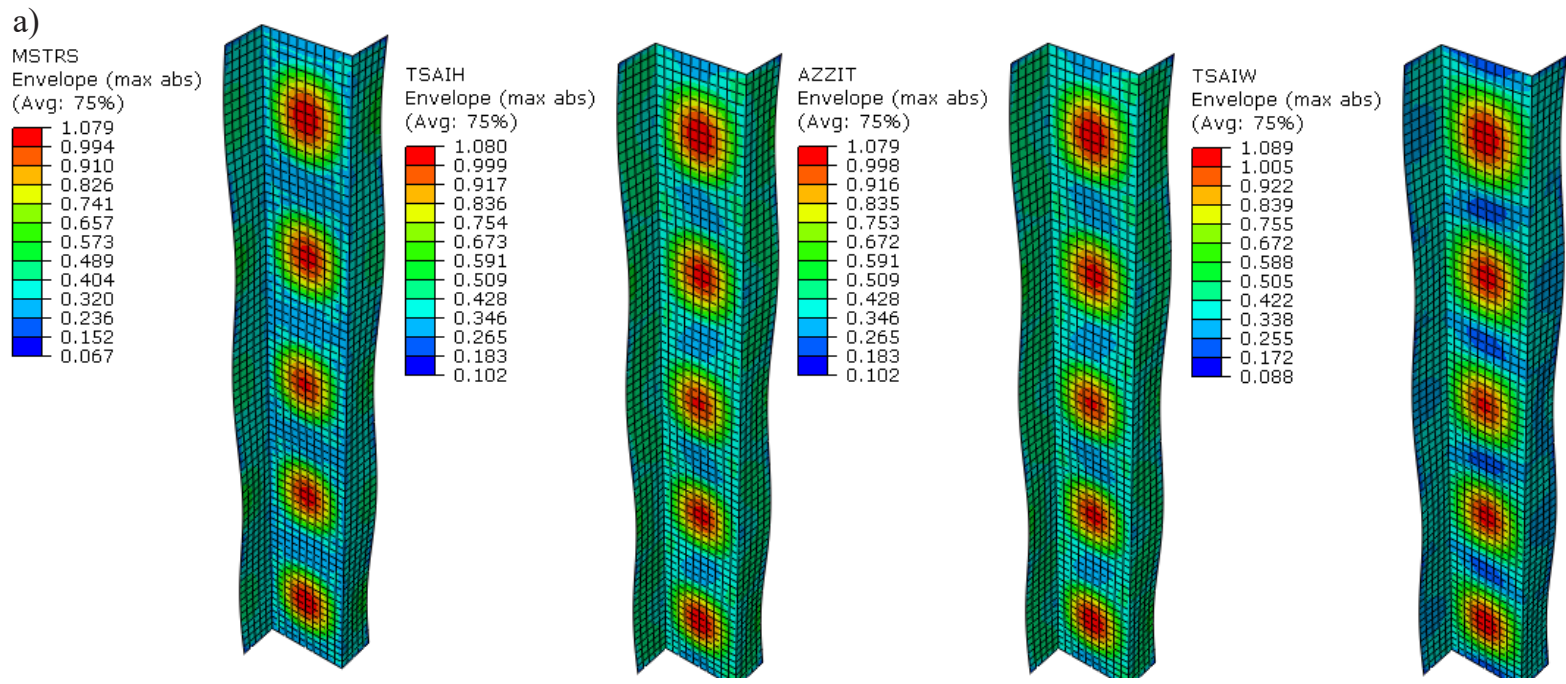

Fig. 4. Graphical representation of the compliance of the initiation criteria: a) Maximum stress criterion, b) TsaiHill criterion, c) Azzi-Tsai-Hill criterion, d) Tsai-Wu criterion 
Table 2. Damage values initiating the destruction depending on the criteria used to destroy the laminate and layering layouts

\begin{tabular}{|c|c|c|c|c|c|}
\hline & $\mathrm{P}_{\text {ini }}[\mathrm{N}]$ & MSTRS & TSAIH & AZZIT & TSAIW \\
\hline$[0 / 90 / 0 / 90] \mathrm{s}$ & 8200 & 1.079 & 1.080 & 1.079 & 1.089 \\
\hline$[90 / 0 / 90 / 0] \mathrm{s}$ & 8000 & 1.059 & 1.059 & 1.059 & 1.059 \\
\hline$[45 /-45 / 0 / 90] \mathrm{s}$ & 11200 & 1.020 & 1.004 & 1.004 & 0.712 \\
\hline$[90 / 0 /-45 / 45] \mathrm{s}$ & 9200 & 1.016 & 1.007 & 1.007 & 1.003 \\
\hline
\end{tabular}

any criterion MSTRS, TSAIH, AZZIT, TSAIW > 1 - this means the initiation of the destruction.

Each initiation criterion was met with the estimated load values initiating the destruction, besides the Tsai-Wu criterion for configuration [45/$45 / 0 / 90] \mathrm{s}$. This case of layer configuration is an exception to the rule, showing relatively convergent values of destructive initiation parameters. In addition, critical load analysis has been shown in [20] where critical load of $\mathrm{P}_{\text {cr }}=12484 \mathrm{~N}$. The damage initiating value is exactly $\mathrm{P}_{\text {ini }}=11200 \mathrm{~N}$, which represents $87 \%$ of the critical load. This shows the potential first signs of damage, already at the stage of structural operations in the state of loss of stability.

The remaining configurations, in regard to the critical loads obtained in the paper [21], show the initiation of destruction at load values significantly higher than the originally determined critical forces. This constitutes the relevance of the work of compressed thin-walled composite structures, where only after reaching critical value, there are further consequences in the form of initiation of damage to the laminate. Table 3 summarizes the values of the critical loads determined by the publication [21] and the forces of destruction initiation.
Table 3. A summary of the critical and initiating burdens depending on the configuration of the laminate layers

\begin{tabular}{|c|c|c|c|}
\hline & $\mathrm{P}_{\text {cr }}[20]$ & $\mathrm{P}_{\text {ini }}$ & $\%$ \\
\hline$[0 / 90 / 0 / 90] s$ & 7311,2 & 8200 & 10,8 \\
\hline$[90 / 0 / 90 / 0] s$ & 7227,6 & 8000 & 9,7 \\
\hline$[45 /-45 / 0 / 90] s$ & 12848 & 11200 & 12,8 \\
\hline$[90 / 0 /-45 / 45] \mathrm{s}$ & 8440,7 & 9200 & 8,3 \\
\hline
\end{tabular}

In addition, the load-displacement characteristics illustrating the initiation points of laminate destruction are shown. The equilibrium paths shown in Figure 5 are based on the measurement of deflection of the central parts of the half-waves demonstrating the greatest deformations, as presented in the publication [21].

The analysis of deep post-critical state - directly related to the study of total destruction of the laminate due to loss of load capacity will be the subject of further research. The post-critical state will be obtained on the basis of the Hashin's initial criterion and the progressive destruction criterion - enabling the testing of the boundary load capacity of the thin-walled composite structures.

\section{CONCLUSIONS}

The analysis of the post-critical state revealed significant correlations between the conducted studies. The sample with the highest degree of stiffness $[45 /-45 / 0 / 90] \mathrm{s}$ configuration proved to be the most susceptible to observing the initiation of laminate destruction. At the moment of loss of stability (when critical force reached), the phenomenon of initiation of damage to the sample occurred. Samples of the other configurations showed similarity

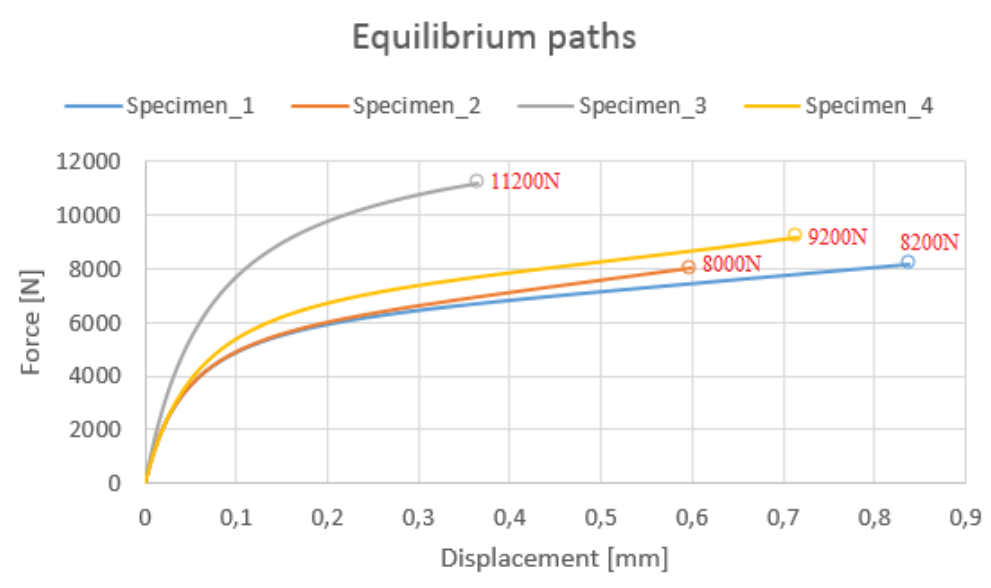

Fig. 5. Presentation of destruction initiation values for equilibrium paths 
in the attainment of the initiation of destruction that occurred only within the range of the original critical load achieved by $8.3-10.8 \%$. The analysis of the specific failure criteria of the laminate was performed, showing a convergence of results within the obtained destruction parameters (the initiation parameter coincides with four independent criteria). In summary, both quantitative and qualitative convergences of initialization parameters for each configuration were obtained.

\section{REFERENCES}

1. Abaqus HTML Documentation.

2. Czapski P., Kubiak T.: Numerical and experimental investigations of the postbuckling behaviour of square cross-section composite tubes. Composite Structures (2015), 132, pp. 1160-1167.

3. Davis J.G.: Compressive Strength of Fiber Reinforced Composite Materials. NASA TM X-71992, 1974.

4. Debski H., Teter A., Kubiak T., Samborski S.: Local buckling, post-buckling and collapse of thin-walled channel section composite columns subjected to quasi-static compression. Composite Structures (2016); 136:593-601.

5. Dębski H.: Badania numeryczne i doświadczalne stateczności i nośności kompozytowych słupów cienkościennych poddanych ściskaniu. Zeszyty naukowe nr 1161, Wydawnictwo Politechniki Łódzkiej, Łódź, 2013.

6. Dębski H.: Experimental investigation post-buckling behaviour of composite column with top-hat cross section. Eksploatacja i Niezawodnosc Maintenance and Reliability (2013); 2:106-110.

7. Falkowicz K., Ferdynus M., Dębski H.: Numerical analysis of compressed plates with a cut-out operating in the geometrically nonlinear range. Eksploatacja i Niezawodnosc - Maintenance and Reliability (2015); 17(2):222-227.

8. Falkowicz K., Mazurek P., Rozylo P., Wysmulski P., Smagowski P.: Experimental and numerical analysis of the compression of a thin-walled composite plate. Advances in Science and Technology - Research Journal (2016); 10(31):177-184.

9. German J.: Podstawy mechaniki kompozytów włóknistych. Politechnika Krakowska, Kraków, 2001.

10. Gliszczynski A., Czechowski L. Collapse of channel section composite profile subjected to bending. Part I: Numerical investigations, Composite Structures 178, 2017, 383-394.

11. Gliszczynski A., Kubiak T. Load-carrying capacity of thin-walled composite beams subjected to pure bending, Thin-Walled Structures 115, 2017, 76-85.

12. Gliszczynski A., Kubiak T. Progressive failure analysis of thin-walled composite columns sub- jected to uniaxial compression, Composite Structures 169, 2017, 52-61.

13. Jenkins C.F.: Materials of construction used in aircraft and aircraft engines. Report to the Great Britain Aeronautical Research Committee, 1920.

14. Klepka T., Dębski H., Rydarowski H. Characteristics of high-density polyethylene and its properties simulation with use of finite element method. Polimery (2009), Vol. 54 Issue 9, 668-672.

15. Kopecki, T., Mazurek, P.: Problems of numerical bifurcation reproducing in postcritical deformation states of aircraft structures. J. Theor. Appl. Mech. 51(4), 969-977 (2013)

16. Kubiak T, Kolakowski Z, Swiniarski J, Urbaniak M, Gliszczynski A.: Local buckling and post-buckling of composite channel-section beams - Numerical and experimental investigations, Composites Part B 2016; 91; 176-188.

17. Molnar V, Fedorko G, Husakova N, Kral J, Ferdynus M.: Energy calculation model of an outgoing conveyor with application of a transfer chute with the damping plate. Mechanical Sciences, vol. 7, issue 2, 2016, pp.167-177.

18. Pignataro M, Luongo A, Rizzi N.: On the effect of the local overall interaction on the postbuckling of uniformaly compressed channels. Thin-Walled Structures 3:283-321;1985.

19. Reddy JN, Pandey AK.: A first-ply failure analysis of composite laminates. Computation Structures, vol. 25, no 3, 1987, pp.371-393.

20. Rozylo P.: Numerical thermal analysis of a car braking system. Advances in Science and Technology - Research Journal (2017); vol. 11, issue 2, pp.38-43.

21. Rozylo P., Lukasik D.: Numerical analysis of the critical state of thin-walled structure with z-profile cross section. Advances in Science and Technology - Research Journal (2017); vol. 11, issue 1, pp.194-200.

22. Rozylo P.: Optimization of I-section profile design by the finite element method. Advances in Science and Technology - Research Journal 2016, 10 (29), pp.52-56.

23. Rozylo P.: Experimental-numerical test of open section composite columns stability subjected to axial compression. Archives of Material Science and Engineering 2017, 84(2), pp.58-64.

24. Rozylo P., Wrzesinska K.: Numerical analysis of the behaviour of compressed thin-walled elements with holes. Advances in Science and Technology Research Journal (2016); 10(31):199-206.

25. Singer J, Arbocz J, Weller T.: Buckling Experiments. Experimental methods in buckling of thin-walled structure. Shells built-up structures, composites and additional topics. Volume 2. John Wiley \& Sons Inc. New York 2002. 
26. Teter, A., Kolakowski, Z.: Load carrying capacity of functionally graded columns with open crosssections under static compression. Compos. Struct. 129, 1-7 (2015).

27. Tsai SW., Wu EM.: A general theory of strength for anisotropic materials. Journal of Composite Materials, vol. 5, nr 1, 1971, str.58-80.

28. Tsai SW.: Strength Theories of Filamentary Structures, in Fundamental Aspects on Fibre Reinforced Plastic Composites. Conference Proceedings, R.
T. Schwartz and H. S. Schwartz (Editors), Dayton, Ohio, 24 - 26 May 1966, Wiley Interscience, str. 3-11, New York, 1968.

29. Wysmulski P., Dębski H., Rozylo P., Falkowicz K.: A study of stability and post-critical behaviour of thin-walled composite profiles under compression. Eksploatacja i Niezawodnosc - Maintenance and Reliability 2016; 18 (4): 632-637.

30.Zienkiewicz O.C., Taylor R.L.: Finite Element Method. Nonlinear. Butterworth, Oxford, 2000. 